\title{
Endüstriyel Hava Kirliliği Toprak Mikro Eklembacaklılarının (Arthropoda) Miktar ve Çeşitliliğini Etkiler Mi?
}

\author{
Ahmet DUYAR ${ }^{1 *}$ \\ ${ }^{1}$ Karabük Üniversitesi, Orman Fakültesi, Orman Mühendisliği Bölümü, 78050, KARABÜK
}

\section{Öz}

Endüstriyel tesislerden çevreye yayılan kirletici atıklar hava, su ve toprak gibi ortamları etkileyerek, ekolojik yapıyı bozabilmektedir. Toprak ekosisteminde önemli rol oynayan toprak mikro eklembacaklıları çevresel değişimlere karşı çok hassas canlılardır. Çimento fabrikaları ve demir çelik tesisleri çevreye yoğun atmosferik kirleticiler bırakmaktadır. Bu çalışmada, Karabük ilindeki çimento ve demir-çelik fabrikasının etraflarındaki toprak mikro eklembacaklılarına olası etkileri araştırılmıştır. Bu amaçla, bahar ve güz mevsimlerinde fabrikaların doğusundaki sırtın fabrikalara bakan ve Karabük Üniversitesi'ne bakan yönlerinde taban, orta yamaç ve üst yamaç olmak üzere 6 noktada üçer tekerrürlü örnekleme yapılmıştır. Toprak örnekleri $5 \mathrm{~cm}$ boy ve $5 \mathrm{~cm}$ çaplı silindir ile üst topraktan $(0-5 \mathrm{~cm})$ alınmıştır. Eklembacaklılar, örneklerden Berlese hunisi yöntemi ile çıkartılmış, mikroskop altında teşhis edilip, sayılmış ve sınıflandırılmıştır. Yapılan çalışmanın sonuçlarına göre, çalışma alanında 61 farklı eklembacaklı taksonu saptanmıştır. Her iki yamaçta da akarlar ve collembolalar en fazla bulunan taksonomik gruplardır. Eklembacaklı sayısı ve Shannon çeşitlilik indeksi $\left(\mathrm{H}^{\prime}\right)$ açısından yamaçlar arasında önemli fark bulunmuştur. Kirlilik etkisi altındaki fabrikaya bakan yamaçta 15463 birey $\cdot \mathrm{m}^{-}{ }^{2}$ ve $\mathrm{H}^{\prime}=1,9$ iken, üniversiteye bakan yamaçta ise 47020 birey $\cdot \mathrm{m}^{-2}$ ve $\mathrm{H}^{\prime}=2,5$ olarak bulunmuştur. Fabrikaya bakan yamaçta eklembacaklı miktarının daha az olması ve biyolojik çeşitlilik indeks değerinin de daha düşük bulunması; endüstriyel kirleticiye doğrudan maruz kalmasının, toprakta yaşayan eklembacaklı taksonlarına belirgin olarak zarar verdiğini düşündürmektedir.

Anahtar Kelimeler: Karabük, Berlese hunisi yöntemi, biyolojik çeşitlilik, Collembola, Akar.

\section{Does Industrial Air Pollution Affect the Amount and Diversity of Soil Microarthropods?}

\begin{abstract}
The pollutant wastes emitted from the industrial facilities can disrupt the ecological structure by affecting the environments such as air, water and soil. Microarthropods, which play an important role in soil ecosystem, are the most sensitive fauna against environmental changes. Cement plants as well as iron-steel plants release intense atmospheric pollutants into the environment. In this study, the possible effects of the iron-steel plant and cement factory in Karabük province on soil microarthropods were investigated. For this aim, in the spring and fall seasons, three replications were sampled at six locations, including the bottom land, the middle hillside and the upper hillside, on the slopes facing the factories of the ridge to the east of the factories and on the opposite sides of the Karabük University. Soil samples were taken from the top soil $(0-5 \mathrm{~cm})$ with a $5 \mathrm{~cm}$ height and $5 \mathrm{~cm}$ diameter cylinder. The arthropods were extracted from the samples by Berlese funnel, identified under the microscope, counted and classified. Based on the results of the study, 61 different arthropod taxa were determined in the study area. Acari and Collembolas are the most abundant taxonomic groups on both hillsides. Significant difference was found between the hillsides in terms of the amount of arthropods and the Shannon diversity index $\left(\mathrm{H}^{\prime}\right)$. Nearly 15463 individuals $\cdot \mathrm{m}^{-2}$ and $\mathrm{H}^{\prime}=1,9$ were identified on the hillside facing the factory under the influence of pollution, while 47020 individuals $\cdot \mathrm{m}^{-2}$ and $\mathrm{H}^{\prime}=2,5$ were found on the hillside facing the university. The fact that the amount of arthropod is lower, and the biodiversity index value is lower on the hillside facing the factory suggests that the direct exposure to the industrial pollutant significantly damages the arthropod taxa in the soil.
\end{abstract}

Keywords: Karabük, Berlese funnel method, biological diversity, Collembola, Acari. 


\section{Giriş}

Endüstriyel tesislerden çevreye yayılan kirletici atıklar hava, su ve toprak gibi ortamları etkileyerek ekolojik yapıyı bozabilmektedir. Karabük Demir Çelik Fabrikasının 1939 yılında kuruluşundan sonra bünyesinde bulunan çalışanlarının değişik çevrelerden göç etmesi ile oluşmuş bir sanayi kentidir. 1937'de 13 haneli bir köy olan Karabük, demir çelik sanayisinin etkisi ile 1994 yılında il olmuş (Özdalyan vd., 2001) ve 2017 yılı il merkezi nüfusu 135000'i geçmiştir (Anonim, 2018). Demir çelik sanayinin yanı sıra, bölgede artarak çoğalan diğer sanayi kuruluşları, konutlar ve iş yerleri; zaman içerisinde çevre ve hava kirliliği kaynağı haline gelmiştir (Hacısalihoğlu, 1994; Anonim, 2017). Karabük il merkezinin çevresi yüksek rakımlı tepe ve dağlarla çevrilmiş olup, neredeyse üç yönden kapalı çanak yapısındadır. Yüksek dağ ve tepeler şehrin hava akışını engellemekte ve madde taşınmasını yavaşlatmaktadır. Karabük’te hâkim rüzgâr yönleri SW, W ve NW ve ortalama rüzgâr hızı 0,8 m/s olarak ifade edilmektedir (Hacısalihoğlu, 1994, Anonim, 2019). Bu koşullarda şehrin bir tarafindan ortama bırakılan kirletici maddeler, tüm şehrin üzerine yayılmaktadır. Çimento fabrikası, demir çelik tesisleri vb sanayi kuruluşları bacalarından havaya ve çevreye kabul edilebilir değerlerin oldukça üzerinde, karbon oksitleri $\left(\mathrm{CO}_{\mathrm{x}}\right)>1000 \mathrm{mg} / \mathrm{l}$, azot oksitleri $\left(\mathrm{NO}_{\mathrm{x}}\right)>1650 \mathrm{mg} / \mathrm{l}$, kükürtlü bileşenler $>1500 \mathrm{mg} / \mathrm{l}$, poliaromatik hidrokarbonlar (PAH) ve partikül maddeler (PM) $625 \mathrm{mg} / \mathrm{l}$ vb kirleticileri saçmaktadır (Hacisalihoğlu, 1994). Şehirdeki hava kirliliği kış mevsiminde ortalama PM için $129 \mu \mathrm{g} \cdot \mathrm{m}^{-}{ }^{3}$ ve $\mathrm{SO}_{2} 48 \mu \mathrm{g} \cdot \mathrm{m}^{-}{ }^{3}$ iken, bu değerler yaz mevsiminde $61 \mu \mathrm{g} \cdot \mathrm{m}^{-}{ }^{3}$ ve $16 \mu \mathrm{g} \cdot \mathrm{m}^{-3}$ olmaktadır (Anonim, 2017). Bunlardan, bir kısmı doğrudan çökelerek, bir kısmı da asit yağışları gibi dolaylı yollarla dönüşerek, toprağa ulaşmaktadır (Fischer vd., 2007).

Çevrenin uzun süre kirletici etkilere maruz kalması, canlı topluluklarını etkileyerek ve ekosistem bütünlüğünü tehlikeye sokarak canlı toplumlarını tehdit etmektedir. Dolayısıyla, biyoçeşitlilik için bir tehdit oluşturmaktadır. $\mathrm{Bu}$ şekildeki bir etkileşim, popülasyonların miktarını, çeşitliliğini, toplum yapısını ve ekosistem faaliyetlerini bozabilir (Tovar-Sánchez, 2018). Toprak ekosisteminin en önemli bileşenlerinden olan, toprak mikro eklembacaklıları ortamdaki değişimlere karşı oldukça hassastır. Toprak biyoçeşitliliği için durum göstergesi olarak en umut verici organizmalar, toprakta barınan omurgasız toprak faunasıdır (Weidema, 2007). Omurgasız toprak faunası, özellikle mikro eklembacaklıların, üreme hızları ve popülasyon boyutları yüksektir. Boyutları küçük olduğu için habitatların yapı ve kalitesine etki edebilecek önemli değişimlerin detaylarının etkin olarak izlenmesini sağlarlar (Nakamura vd., 2003; Faber ve Wensem, 2012). Butnariu, (2015) kirlenmiş toprağın fiziksel ve kimyasal yapısı bozulduğunda, içerisindeki mikroorganizma faaliyetlerini etkilenerek toprakta yetişen floranın ve barınan faunanın zarar göreceğini ifade etmektedir. Topraktaki ağır metal kirliliğinin biyolojik göstergesi olarak Collembola gibi bazı eklembacaklı taksonlarının kullanılabileceğini ifade etmektedir (Posthuma, 1990; An vd., 2013).

Karabük’teki çimento ve demir-çelik fabrikalarının neden olduğu kirliliğin toprak omurgasız faunası üzerindeki etkisinin belirlenmesi kapsamında ilk çalışma 2016 y1lında gerçekleştirilmiştir (Duyar, 2017). Fabrikaların toprak faunası üzerindeki zararlı etkisinin belirlenmesi üzerine, araştırma geliştirilmiştir. Kirletici etkisine en hassas taksonlardan olan Collembola sınıfi ile sahanın toprak özelliklerini incelemek için 2017 yılında yeni bir çalışma yürütülmüştür (Duyar, 2018a).

$\mathrm{Bu}$ çalışmada, endüstri kaynaklı kirliliğin, toprak eklembacaklı faunası üzerindeki etkisinin belirlenmesi amaçlanmıştır. Bu doğrultuda, 2017 yılında alandan alınan örnekler Collembola sınıfi haricindeki diğer taksonlar da tekrar incelenip, sayılarak sınıflandırılmıştır. Elde edilen veriler birlikte ele alınarak, toprak eklembacaklı faunasının tüm taksonlarının miktarı, çeşitliliği, toplum yapıları, besin ağındaki pozisyonları, toprak özellikleriyle ve birbirleriyle olan ilişkileri değerlendirilmiştir.

\section{Materyal ve Metot}

\section{1. Çalışma Alanı}

Çalışma, Karabük ilinin güney-batısında yer alan çimento ve demir çelik fabrikalarının civarında yapılmıştır. Örnek alanlar, fabrikaların doğusundaki sırtın fabrikalara bakan (etkilenen) ve aksi yönünde Karabük Üniversitesi'nin bulunduğu (kontrol) yamaçlarda seçilmiştir (Şekil 1). Örneklemeler 2017 yılının bahar ve güz mevsimlerinde birer kez yapılmıştır. Örnekler sırtın her iki yönünde de taban, orta yamaç ve üst yamaçtan olmak üzere, her mevsim için toplam 6 noktada üçer tekerrürlü olarak alınmıştır. 

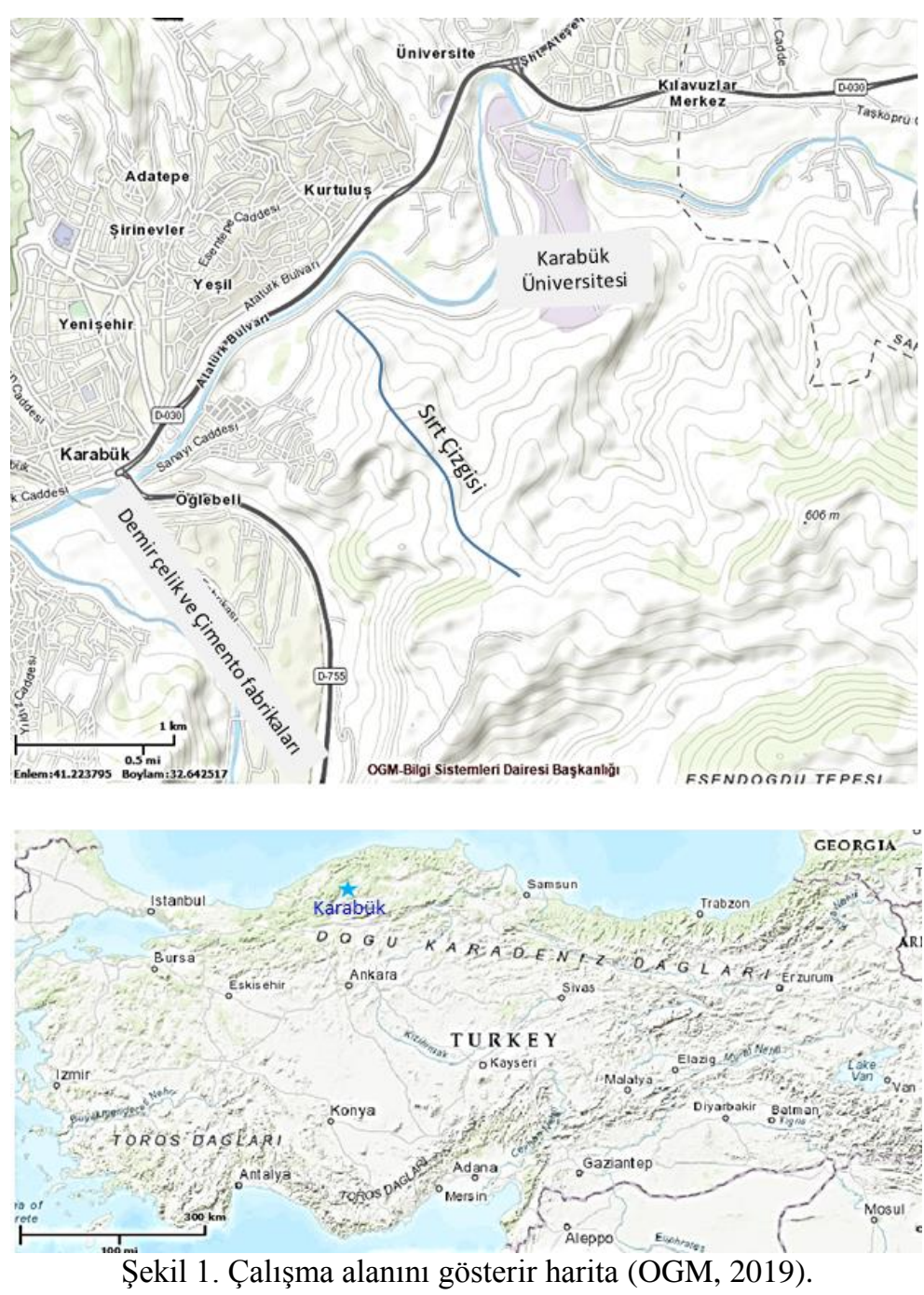

\section{2. Çalışma Alanının Toprak Özellikleri}

Toprak analizleri için $5 \mathrm{~cm}$ çapındaki ve $5 \mathrm{~cm}$ yüksekliğindeki hacim silindirleri ile $0-5 \mathrm{~cm}$ üst toprak derinliğinden alınmıştır (Duyar ve Makineci, 2016). Alınan toprak örneklerinin taze ve kurutulmuş (24 saat 105 $\left.{ }^{\circ} \mathrm{C}\right)$ ağırlıkları kullanılarak, hacim ağırlıkları, gözeneklilik oranı ve toprak nemi belirlenmiştir (Karaöz, 1989). Daha sonra porselen havanlarda ögütülmüş, taş ve köklerinden ayrilarak $2 \mathrm{~mm}$ 'lik eleklerden elenerek, Bouyoucus hidrometre metodu ile toprak türü (kum, toz ve kil oranları) ve iskelet miktarı bulunmuştur. Ayrıca, asitlik $(\mathrm{pH}) 1 / 2,5$ toprak/su çözeltisinde ve elektriksel iletkenlik (EC) analizleri 1/5 toprak/su çözeltisinde yapılmıştır (Gülçur, 1974).

Çalışma alanındaki toprak özelliklerinin yamaçlara göre dağılımında; fabrika tarafında kum \%56, toz \%21, kil $\% 23$, asitlik 7,9 pH, elektriksel iletkenlik $258 \mu$ mhos $/ \mathrm{cm}$, nem \%12,5, iskelet içeriği \%11,5, gözenek hacmi $\% 54$ ve hacim ağırlığı $1150 \mathrm{~g} /$ l'dir. Üniversite tarafındaki yamaçta ise kum $\% 11$, toz $\% 25$, kil \%64, asitlik 7,8 $\mathrm{pH}$, elektriksel iletkenlik $267 \mu \mathrm{mhos} / \mathrm{cm}$, nem \%24,5, iskelet içeriği \%2,1, gözenek hacmi \%54,1, hacim ağırlı̆̆1 $1148 \mathrm{~g} / 1$ olarak bulunmuştur (Duyar, 2018a).

\subsection{Eklembacaklıların Araziden Örneklenmesi}

Eklembacaklıların araziden örneklenmesinde bozulmamış toprak örnekleri için $5 \mathrm{~cm}$ çapında çelik silindirler kullanılmıştır (Meehan vd., 2006). Toprak örnekleri 0-5 cm üst toprak derinliğinden, $5 \times 5 \mathrm{~cm}$ silindirle her örnekleme noktasından 3 tekerrürlü toprak örneği alınmıştır. Eklembacaklıların örneklendiği silindirler, toprak içerisindeki nemi, doğal gözenek yapısını ve canlıların yollarını koruyacak şekilde, polietilen folyo ile kaplanmıştır. Örnekler, etiketlenerek, kasalara yerleştirilip, laboratuvara taşınmıştır. Laboratuvarda bekletilmeden, aynı gün ekstraksiyon işlemine başlanmıștır (Duyar, 2014). 


\subsection{Toprak Örneklerinden Eklembacaklıların Çıkartılması}

Bu çalışmada, toprak canlılarının 1sı ve ışıktan kaçarak toprağın derinliklerine doğru hareket etmesi prensibine dayanan modifiye Tullgren (Berlese) hunisi kullanılmıştır (Coleman vd., 2004). Araziden çelik silindirler ile

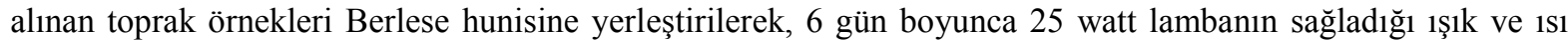
altında bekletilmiștir (Dombos, 2002). Böylece eklembacaklılar topraktaki doğal kanalları kullanarak, alttaki toplama kabında \%70'lik etil alkol + \%2 gliserin içeren sıvı içerisinde birikmiştir (Joo vd., 2006).

\subsection{Eklembacaklıların Teşhisi ve Sınıflandırılması}

Toprak örneklerinden elde edilen eklembacaklı örneklerinin teşhis, tasnifleri ve sayımları laboratuvar ortamında gerçekleştirilmiştir. Özellikle mikro eklembacaklılar, çıplak gözle tanımlanamayacak kadar küçük oldukları için, tüm örnekler 7x-180x büyütmeli, stereo zoom mikroskop kullanılarak teşhis ve tasnif edilerek, sayılmıştır (Salmon vd., 2006). Sınıflandırma, takson seviyesinde yapılmıştır (Santos vd., 2007).

\section{6. İstatiksel Değerlendirme}

Örneklerden elde edilen eklembacaklıların miktarı birey $\mathrm{m}^{-2}$ olarak değerlendirmeye alınmıştır. Toprak özellikleri ve eklembacaklı verilerin istatistiksel olarak değerlendirilmesinde, $\%$ oranları, korelasyon ve tek yönlü varyans analizleri kullanılmıştır. Değişkenler arasında Kanonik Uyum Analizi (CCA) ve grafikleri yapılarak önemli $\quad(\mathrm{P}<0.05)$ ilişkiler belirlenmiştir. Ayrıca örnek alanlardan elde edilmiş toprak eklembacaklılarının biyolojik çeşitliliğini ortaya koymak için; Shannon çeşitlilik indeksi $\left(\mathrm{H}^{\prime}\right)$ ve takson sayısını ifade eden taksonomik zenginlik (S') kullanılmıştır (Özkan, 2012).

\section{Bulgular ve Tartışma}

Bu çalışma kapsamında Collembola sınıfı (Tablo 1) haricinde, aynı örnekler içerisinden 16 farklı taksonomik grup daha teşhis ve tasnif edilmiştir (Tablo 2). Örneklerde kullanılan silindirlerin temsil ettiği alanda $\left(\approx 20 \mathrm{~cm}^{2}\right)$ belirlenen eklembacaklıların oluşturduğu topluluklar, 1 ila 31 farklı taksondan meydana gelmiş ve 1 ila 163 bireyden oluşmaktadır. Tablo 1 ve Tablo 2 birlikte ele alındığında, yamaçlar hem kendi içlerinde hem de genel olarak değerlendirildiğinde taksonların topluluklarda bulunma miktarları da ve oranları da farklıdır. Eklembacaklı taksonlarının yamaçlara dağılımı incelendiğinde; ortalama olarak fabrikalar tarafında (15463 birey $\cdot \mathrm{m}^{-2}$ ), üniversite tarafına (47020 birey $\cdot \mathrm{m}^{-2}$ ) göre daha az birey bulunmuştur. Bazı nadir bulunan taksonlar istisna tutulursa diğer tüm taksonlar üniversiteye bakan yamaçta, fabrikaya bakan yamaçtan yaklaşık 3 kat daha fazla bulunmuştur. Fabrika tarafindaki yamaçtaki bu farklılığın temel nedeninin kirletici kaynağına yakınlık ve baca gazına doğrudan maruziyeti olduğu düşünülmektedir. Santorufo vd., (2012) metalik kirlenmelerin eklembacaklı taksonları için toksik etkiye sahip olduğunu ifade etmektedir.

Tablo 1. Collembola sınıfı eklembacaklı taksonlarının dağılımı (Birey $\cdot \mathrm{m}^{-2}{ }^{2}$ ) (Duyar, 2018a).

\begin{tabular}{clcccccc}
\hline \multirow{2}{*}{$\begin{array}{c}\text { Kod } \\
\text { No }\end{array}$} & \multirow{2}{*}{ Taksonlar } & \multicolumn{2}{c}{ Yamaçlar } & & $\begin{array}{c}\text { Toplumdaki } \\
\text { Oranı }\end{array}$ & $\begin{array}{c}\text { Ortalama } \pm \\
\text { Standart } \\
\text { Sapma }\end{array}$ & P \\
\cline { 3 - 4 } & & $\begin{array}{c}\text { Fabrika } \\
\text { Yönü }\end{array}$ & $\begin{array}{c}\text { Üniversite } \\
\text { Yönü }\end{array}$ & \% & & \\
\hline 1 & Onychiuridae & 614 & 2378 & & 4,8 & $1496 \pm 2403$ & 0,025 \\
2 & Hypogastruridae & 1442 & 2854 & & 6,9 & $2148 \pm 4636$ & 0,369 \\
3 & Entomobryidae & 1258 & 1657 & & 4,7 & $1457 \pm 1816$ & 0,518 \\
4 & Isotomidae & 522 & 2071 & & 4,1 & $1296 \pm 1693$ & 0,004 \\
5 & Neelidae & 92 & 736 & & 1,3 & $414 \pm 1076$ & 0,072 \\
6 & Sminthuridae & 31 & 644 & & 1,1 & $337 \pm 878$ & 0,034 \\
\hline
\end{tabular}

Çalışma alanında genel olarak en baskın taksonomik gruplar akarlar (Acarina \%66) ve sıçrar kuyruklar (Collembola \%23) olup, akarlar içerisinde en fazla rastlanılan takson Oribatida $(\% 36,9)$ iken Collembolalar içerisinde ise Hypogastruridae $(\% 6,9)$ olmuştur (Tablo1 ve Tablo 2). Araneae sınıfına ait akarlar takımı dışındaki diğer taksonlar topluluklarda nadir olarak tespit edilmiştir (Tablo 2). Toprak eklembacaklılarının toplumda 
bulunma oranları Bolu, Karabük ve Araç ormanlarında yapılan çalışmada benzer oranlarda bulunmuştur (Duyar ve Makineci, 2016; Duyar, 2018b).

Tablo 2. Collembola sınıfı dışındaki eklembacaklı taksonlarının dağılımı (Birey·m $\left.{ }^{2}\right)$.

\begin{tabular}{|c|c|c|c|c|c|c|}
\hline \multirow{2}{*}{$\begin{array}{c}\text { Kod } \\
\text { No }\end{array}$} & \multirow{2}{*}{ Taksonlar } & \multicolumn{2}{|c|}{ Yamaçlar } & \multirow{2}{*}{$\begin{array}{c}\text { Toplumdaki } \\
\text { Oranı } \\
\%\end{array}$} & \multirow{2}{*}{$\begin{array}{c}\text { Ortalama } \pm \\
\text { Standart } \\
\text { Sapma }\end{array}$} & \multirow{2}{*}{$\mathbf{P}$} \\
\hline & & $\begin{array}{c}\text { Fabrika } \\
\text { Yönü }\end{array}$ & $\begin{array}{c}\text { Üniversite } \\
\text { Yönü }\end{array}$ & & & \\
\hline 7 & Oribatida & 3988 & 19070 & 36,9 & $11529 \pm 13137$ & 0,000 \\
\hline 8 & Mesostigmata & 1994 & 4617 & 10,6 & $3306 \pm 3813$ & 0,037 \\
\hline 9 & Prostigmata & 3497 & 7716 & 17,9 & $5607 \pm 5521$ & 0,020 \\
\hline 10 & Astigmata & 61 & 307 & 0,6 & $184 \pm 544$ & 0,180 \\
\hline 11 & Opiliones & 31 & 92 & 0,2 & $61 \pm 220$ & 0,411 \\
\hline 12 & Pseudoscorpiones & 0 & 92 & 0,1 & $46 \pm 203$ & 0,178 \\
\hline 13 & Chilopoda & 61 & 0 & 0,1 & $31 \pm 128$ & 0,154 \\
\hline 14 & Diplopoda & 31 & 184 & 0,3 & $107 \pm 473$ & 0,337 \\
\hline 15 & Symphyla & 245 & 675 & 1,5 & $460 \pm 798$ & 0,107 \\
\hline 16 & Pauropoda & 184 & 215 & 0,6 & $199 \pm 497$ & 0,856 \\
\hline 17 & Protura & 522 & 767 & 2,1 & $644 \pm 850$ & 0,395 \\
\hline 18 & Diplura & 0 & 322 & 0,5 & $161 \pm 468$ & 0,037 \\
\hline 19 & Diptera & 276 & 92 & 0,6 & $184 \pm 457$ & 0,232 \\
\hline 20 & Larva & 31 & 291 & 0,5 & $161 \pm 339$ & 0,019 \\
\hline 21 & Coleoptera & 61 & 123 & 0,3 & $92 \pm 247$ & 0,464 \\
\hline 22 & Hymenoptera & 307 & 1918 & 3,6 & $1112 \pm 2257$ & 0,030 \\
\hline 23 & Thysanoptera & 31 & 92 & 0,2 & $61 \pm 220$ & 0,411 \\
\hline 24 & Isopoda & 184 & 107 & 0,5 & $146 \pm 404$ & 0,576 \\
\hline
\end{tabular}

Örneklerden elde edilen eklembacaklı topluluklarının büyük kısmını (\%95) oluşturan 12 takson dikkate alındığında bunların neredeyse tamamının akarlar ve collembolalardan oluştuğu görülmektedir. Bu en fazla rastlanılan taksonların toprak özellikleri (Duyar, 2018a) ile ilişkisi incelenerek yaşama ortamı tercihleri belirlenmiştir. Akarlar, bazı collembolalar ve karıncalar (Hymenoptera) belirgin olarak kirlilikten etkilenen yamaçtan kaçınmışlar ve kontrol alanında daha fazla bulunmuşlardır. Aynı taksonlar benzeri davranışı kum oranı ile negatif, kil oranı ile pozitif korelasyon göstermektedir (Tablo 3).

Tablo 3. Toprak eklembacaklılarının toprak özellikleri ile korelasyonu.

\begin{tabular}{|c|c|c|c|c|c|c|c|c|c|c|}
\hline $\begin{array}{c}\text { Kod } \\
\text { No }\end{array}$ & Taksonlar & $\begin{array}{c}\text { Toplumdaki } \\
\text { \% Oranı }\end{array}$ & Yamaç & pH & EC & $\underset{\%}{\text { Kum }}$ & $\begin{array}{c}\text { Kil } \\
\%\end{array}$ & $\begin{array}{c}\text { Nem } \\
\%\end{array}$ & $\begin{array}{c}\text { Gözenek } \\
(\%)\end{array}$ & $\begin{array}{c}\text { Hacim } \\
\text { Ağırlığı }\end{array}$ \\
\hline 7 & Oribatida & 36,9 & $0,582^{* *}$ & $-0,257$ & 0,206 & $-0,570^{* *}$ & $0,607^{* * *}$ & 0,261 & 0,064 & $-0,064$ \\
\hline 9 & Prostigmata & 17,9 & $0,387^{*}$ & $-0,482^{* *}$ & $0,563^{* *}$ & $-0,343^{*}$ & $0,376^{*}$ & 0,115 & $\mathbf{0 , 3 3 4 ^ { * }}$ & $-0,334^{*}$ \\
\hline 8 & Mesostigmata & 10,6 & $0,349^{*}$ & $-0,298$ & $0,562^{* *}$ & $-0,386^{*}$ & $0,389^{*}$ & 0,290 & $0,387^{*}$ & $-0,387^{*}$ \\
\hline 2 & Hypogastruridae & 6,9 & 0,154 & $-0,320$ & $0,508^{* *}$ & $-0,208$ & 0,211 & 0,097 & 0,140 & $-0,140$ \\
\hline 1 & Onychiuridae & 4,8 & $0,372^{*}$ & $-0,386^{*}$ & $\mathbf{0 , 5 8 0}{ }^{* *}$ & $-0,375^{*}$ & $0,364^{*}$ & 0,226 & $0,404^{*}$ & $-0,404^{*}$ \\
\hline 3 & Entomobryidae & 4,7 & 0,111 & $-0,279$ & 0,319 & $-0,186$ & 0,183 & 0,233 & 0,044 & $-0,044$ \\
\hline 4 & Isotomidae & 4,1 & $0,464^{* *}$ & $-0,493^{* *}$ & $0,362^{*}$ & $-0,484^{* *}$ & $0,498^{* *}$ & 0,182 & 0,193 & $-0,193$ \\
\hline 22 & Hymenoptera & 3,6 & $0,362^{*}$ & $-0,002$ & $-0,184$ & $-0,392^{*}$ & $0,442^{* *}$ & $\mathbf{0 , 5 5 8} 8^{* *}$ & $-0,016$ & 0,016 \\
\hline 17 & Protura & 2,1 & 0,146 & $-0,321$ & 0,248 & $-0,144$ & 0,121 & 0,247 & 0,079 & $-0,079$ \\
\hline 15 & Symphyla & 1,5 & 0,273 & $-0,256$ & 0,189 & $-0,328$ & $0,376^{*}$ & $0,448^{* *}$ & 0,094 & $-0,094$ \\
\hline 5 & Neelidae & 1,3 & 0,304 & $-0,240$ & 0,297 & $-0,248$ & 0,201 & 0,055 & 0,315 & $-0,315$ \\
\hline 6 & Sminthuridae & 1,1 & $\mathbf{0 , 3 5 4}{ }^{*}$ & $-0,166$ & 0,222 & $-0,296$ & 0,265 & 0,044 & 0,280 & $-0,280$ \\
\hline
\end{tabular}

Wiwatwitaya ve Takeda (2005) toprak neminin, eklembacaklıların miktarı üzerine olumlu etki yaptığını ifade etmesine rağmen, bu çalışmada toprak nemi ile Hymenoptera ve Symphyla taksonları pozitif korelasyon 
göstermiştir. Bunun sebebi olarak, bu çalışmanın bahar ve güz mevsimlerinde yapılması nedeniyle, diğer taksonların varlığını etkileyecek aşırı nem açığı bulunmaması biçiminde açıklamak mümkündür.

Eklembacaklıların bazı çevresel özelliklerle ilişkisini belirlemek için yapılan Kanonik Uyum Analizine göre, Oribatida taksonu kil oranından, Symphyla taksonu hem kil hem de nem oranından pozitif yönde etkilenmektedir. Diplopoda, Chilopoda ve Opiliones taksonları EC değerinden pozitif yönde etkilenirken, Onychiuridae, Hypogastruridae, Neelidae ve Mesostigmata taksonları toprak hacim ağırlığı (yoğunluk) ve kil oranından negatif yönde etkilenmektedir. Ancak CCA grafiğine göre diğer taksonların çevresel özelliklerle anlamlı bir etkileşim belirlenememiştir (Şekil 3).

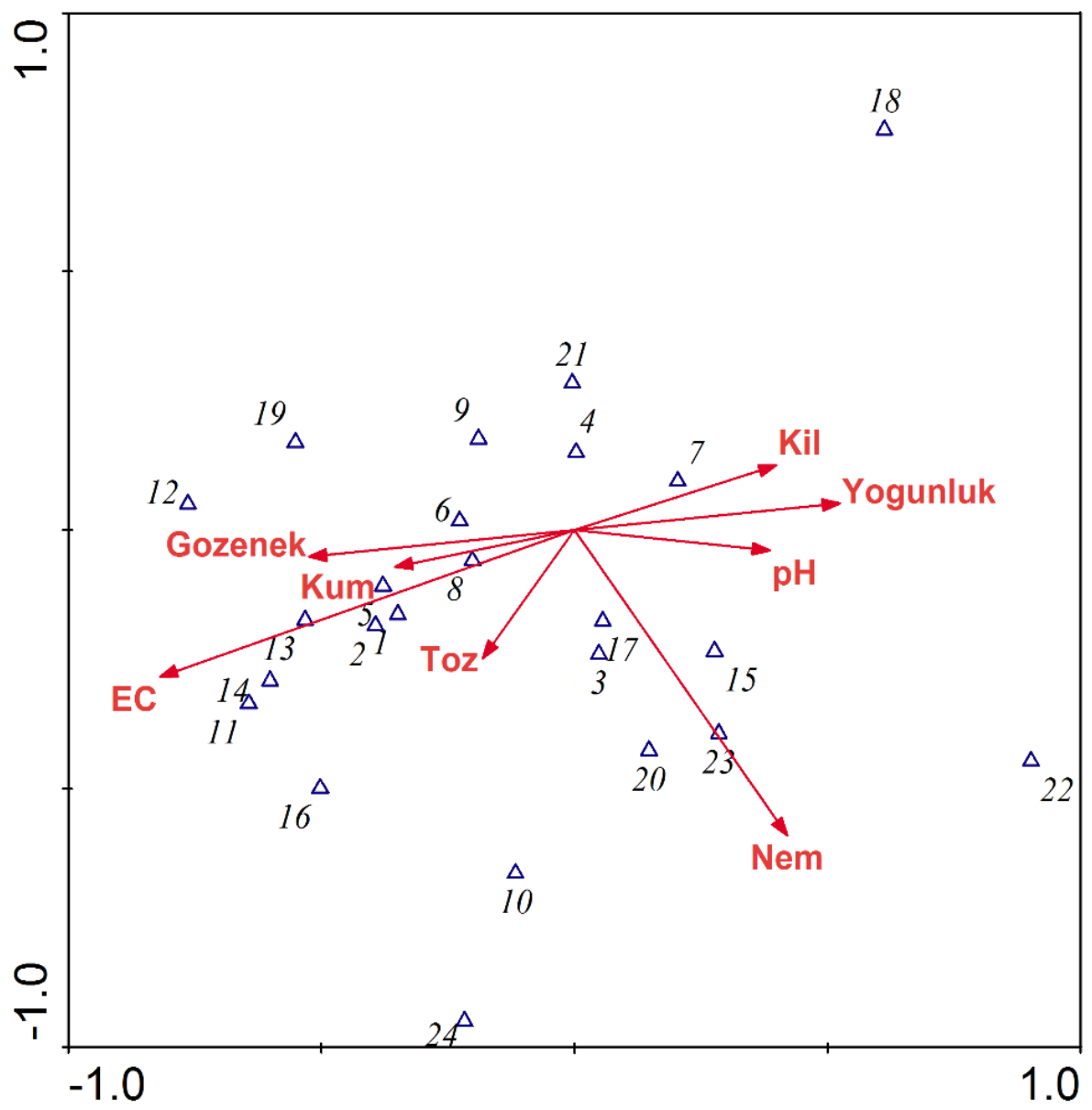

Şekil 3. Eklembacaklıların bazı çevresel özelliklerle ilişkisine ait CCA grafiği.

Onychiuridae ve Neelidae taksonları tümüyle hipogeik (toprak altında) yaşayan eklembacaklılardandır. Hypogastruridae ve Mesostigmata taksonları ise şartlara göre hem hipogeik hem de (epigeik) toprak yüzeyinde yaşayabilmektedir (Duyar, 2018b). Hipogeik yaşam süren taksonlar, toprak sıkışıklığ 1 veya toprak gözeneklerinin su ile dolması gibi yaşam ortamlarını ortadan kaldıran fiziksel değişimlerden en fazla etkilenen grubu oluşturmaktadır. Duyar (2014) ormanlarda mineral toprak gözeneklerinin su ile dolduğu kış şartlarında, hipogeik taksonların nispeten daha az nem tutan ve daha gözenekli olan, ölü örtü tabakasına doğru göç ederek, kışın ölü örtü içerisinde diğer mevsimlere göre daha fazla sayıda yer aldıklarını ifade etmektedir.

Toprak ekosisteminde tespit edilen eklembacaklı taksonlarının oluşturduğu toplumda, taksonların birbiri ile ilişkileri korelasyon analizi ile ortaya konmuştur. Toplumun \%95'lik oranı oluşturan, en yaygın 12 takson içerisinde Mesostigmata ve Onychiuridae 9 takson ile; Isotomidae ve Symphyla 7 takson ile pozitif ilișkilidir. Bununla birlikte taksonlar arasında negatif yönlü ilişkiye rastlanmamıştır (Tablo 4). Aynı zamanda, çalışılan 36 örnek içerisinde Oribatida 34, Prostigmata 32, Mesostigmata 28 ve Entomobryidae 26 örnek ile en yaygın rastlanan taksonlardır. 
Tablo 4. Toprak ekosistemindeki eklembacaklılarının birbirleri ile korelasyonu.

\begin{tabular}{|c|c|c|c|c|c|c|c|c|c|c|c|c|}
\hline Taksonlar & $\begin{array}{c}\text { Oranı } \\
(\%)\end{array}$ & 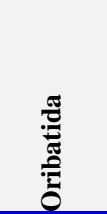 & 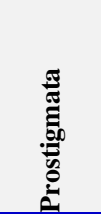 & 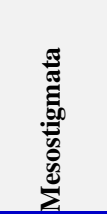 & 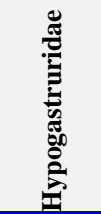 & 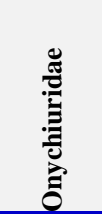 & 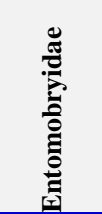 & 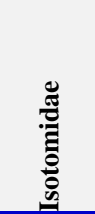 & 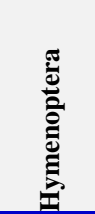 & 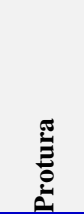 & 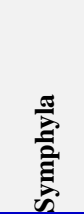 & 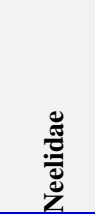 \\
\hline Oribatida & 36,9 & 1 & & & & & & & & & & \\
\hline Prostigmata & 17,9 & 0,321 & 1 & & & & & & & & & \\
\hline Mesostigmata & 10,6 & $0,422^{*}$ & $0,663^{* *}$ & 1 & & & & & & & & \\
\hline Hypogastruridae & 6,9 & $0,365^{*}$ & $\mathbf{0 , 3 3 8}{ }^{*}$ & $0,564^{* *}$ & 1 & & & & & & & \\
\hline Onychiuridae & 4,8 & $\mathbf{0 , 4 1 1 ^ { * }}$ & $0,711^{* *}$ & $\mathbf{0 , 7 3 0}{ }^{* *}$ & $0, \mathbf{5 3 8}^{* *}$ & 1 & & & & & & \\
\hline Entomobryidae & 4,7 & 0,327 & 0,232 & $\mathbf{0 , 3 3 6} 6^{*}$ & 0,217 & $0,505^{* *}$ & 1 & & & & & \\
\hline Isotomidae & 4,1 & $0,405^{*}$ & $0,407^{*}$ & $\mathbf{0 , 5 1 2}{ }^{* *}$ & $0,492^{* *}$ & $0,562^{* *}$ & $\mathbf{0 , 3 8 8 ^ { * }}$ & 1 & & & & \\
\hline Hymenoptera & 3,6 & $-0,076$ & $-0,123$ & $-0,119$ & $-0,213$ & $-0,163$ & 0,163 & 0,136 & 1 & & & \\
\hline Protura & 2,1 & $0,516^{* * *}$ & 0,230 & 0,250 & 0,262 & 0,216 & $0,498^{* *}$ & 0,223 & $-0,159$ & 1 & & \\
\hline Symphyla & 1,5 & 0,155 & $0,341^{*}$ & $0,391^{*}$ & $0,364^{*}$ & $0,335^{*}$ & $0,504^{* *}$ & $0,346^{*}$ & $0,371^{*}$ & 0,180 & 1 & \\
\hline Neelidae & 1,3 & 0,264 & $0,356^{*}$ & $0,570^{* *}$ & 0,220 & $0,529^{* *}$ & 0,249 & 0,089 & $-0,174$ & 0,205 & 0,147 & 1 \\
\hline Sminthuridae & 1,1 & $\mathbf{0 , 4 5 1 ^ { * * }}$ & 0,281 & $0,487^{* *}$ & 0,223 & $\mathbf{0 , 5 2 2} 2^{* *}$ & 0,229 & 0,067 & $-0,182$ & 0,167 & 0,033 & $0,927^{* *}$ \\
\hline
\end{tabular}

Eklembacaklıların biyolojik çeşitliliği yamaçlar arasında belirgin olarak farklıdır. Shannon çeşitlilik indeksi $\left(\mathrm{H}^{\prime}\right)$ yamaçlar arasında farklı olmakla birlikte, örnekleme noktaları arasında anlamlı farklı değildir. Yine de en düşük $\mathrm{H}^{\prime}$ değeri 3 nolu noktada $\left(\mathrm{H}^{\prime}=1,75\right)$ ortaya çıkarken, en yüksek değer 5 nolu noktada $\left(\mathrm{H}^{\prime}=2,64\right)$ ortaya çıkmıştır. Fabrikaya bakan yamacın ortalaması $\mathrm{H}^{\prime}=1,91$ iken, diğer yamacın ortalaması $\mathrm{H}^{\prime}=2,52$ 'dır. Taksonomik zenginlik $\left(S^{\prime}\right)$ açısından değerlendirildiğinde de üniversiteye bakan yamacın taksonomik zenginliği $\left(S^{\prime}=20,5\right)$ fabrikalara bakan yamaçtan $\left(S^{\prime}=11\right)$ daha zengin olduğu görülmektedir (Tablo 5). Hava ve trafik kirliliğine maruz kalan Bükreş şehir parklarında yapılan bir çalışmada, Fiera (2009) eklembacaklı biyoçeşitliliğinin şehir kirliliğinden etkilendiğini ve taksonomik zenginliğin kirlenme ile ters orantılı olarak değiștiğini belirtmektedir. Örnek noktaların biyoçeşitlilik değerleri arasındaki farklılığın nedenlerinin başında fabrikalardan kaynaklanan kirleticilerin (PAH, PM vb) etkisi olduğu düşünülmektedir. Söz konusu kirleticilerin eklembacaklı varlığını hem miktar hem de çeşitlilik olarak olumsuz etkilediği değerlendirilmektedir. Mikro boyutlu plastikler topraktaki besin ağı içerisinde taşınarak ve vücut içerisinde birikerek, fauna üzerine toksik etkiye yol açmaktadır (Maaß vd., 2017).

Tablo 5. Eklembacaklıların biyolojik çeşitliliği.

\begin{tabular}{|c|c|c|c|c|}
\hline \multirow[b]{2}{*}{ Örnek Noktalar } & \multicolumn{2}{|c|}{ Shannon Çeșitlilik İndeksi $\left(\mathrm{H}^{\prime}\right)$} & \multicolumn{2}{|c|}{ Taksonomik Zenginlik (S') } \\
\hline & $\begin{array}{c}\text { Ortalama } \pm \\
\text { Standart Sapma }\end{array}$ & $\begin{array}{c}\text { Yamaç } \\
\text { ortalaması }\end{array}$ & $\begin{array}{c}\text { Ortalama } \pm \\
\text { Standart Sapma } \\
\end{array}$ & $\begin{array}{c}\text { Yamaç } \\
\text { ortalaması }\end{array}$ \\
\hline 1- Fabrikalar Alt Yamaç & $2,06 \pm 0,64$ & & $11,5 \pm 6,1$ & \\
\hline 2- Fabrikalar Orta Yamaç & $1,91 \pm 0,46$ & $1,91 \pm 0,76$ & $8,7 \pm 4,7$ & $11 \pm 7,9$ \\
\hline 3- Fabrikalar Üst Yamaç & $1,75 \pm 1,14$ & & $12,8 \pm 12$ & \\
\hline 4- Üniversite Alt Yamaç & $2,34 \pm 0,64$ & & $17,5 \pm 8,6$ & \\
\hline 5- Üniversite Orta Yamaç & $2,64 \pm 0,33$ & $2,52 \pm 0,44$ & $23,2 \pm 6,4$ & $20,5 \pm 6,9$ \\
\hline 6- Üniversite Üst Yamaç & $2,57 \pm 0,27$ & & $20,8 \pm 5,4$ & \\
\hline Ortalama & \multicolumn{2}{|c|}{$2,21 \pm 0,69$} & \multicolumn{2}{|c|}{$15,7 \pm 8,8$} \\
\hline $\mathrm{P}$ & 0,129 & 0,006 & 0,017 & 0,001 \\
\hline
\end{tabular}

Eklembacaklılar besin ağındaki trofik seviyelerine göre gruplandırıldığında, saprofit beslenen çürükçüller toplum içerisinde en fazla (>\%50) bireyi içermektedir. İkinci sırada yaklaşık \%30'luk bir sayı ile etçil beslenen karnivorlar yer almaktadır. Otçul ve hepçil beslenen bireylerin oranı ise \%10 civarındadır (Tablo 6). Karnivorlar ile diğer faunanın oranı ekosistem besin ağı açsından dengededir. Duyar (2014) orman toprağında yaptığı çalışmada yaklaşık olarak, saprofitlerin oranını \%70, yırtıcıların oranının da \%25 olduğunu belirtmektedir. Besin ağının içerdiği trofik seviyelerdeki birey oranları, kontrol alanında doğal ormana daha yakın bulunmuştur. Kirlilikten etkilenen yamaçta ise özellikle saprofit beslenen bireylerin oranı $(\% 50,6)$ normal ormana kıyasla oldukça düşük bulunmuştur. Söz konusu bulgulardan hareketle kirleticilerin özellikle çürükçül beslenen gruplar üzerinde olumsuz etkisi olduğu, dolayısıyla da besin ağındaki av avcı ilişkileri çerçevesinde yırtıcılar başta olmak üzere diğer grupları da etkilediği kanaatine varılmaktadır. 
Tablo 6. Eklembacaklı taksonlarının trofik seviyelere dağılımı.

\begin{tabular}{|c|c|c|c|c|}
\hline \multirow{2}{*}{ Trofik Seviye } & \multicolumn{2}{|c|}{ Fabrika tarafi } & \multicolumn{2}{|c|}{ Üniversite tarafı } \\
\hline & $\left(\right.$ Birey $\left.\cdot \mathrm{m}^{-2}\right)$ & Oranı (\%) & $\left(\right.$ Birey $\left.\cdot m^{-2}\right)$ & Oranı (\%) \\
\hline Saprofit & 7824 & 50,6 & 29379 & 62,5 \\
\hline Herbivor & 1320 & 8,5 & 2393 & 5,1 \\
\hline Karnivor & 5705 & 36,9 & 12947 & 27,5 \\
\hline Omnivor & 614 & 4 & 2301 & 4,9 \\
\hline Toplam & 15463 & 100 & 47020 & 100 \\
\hline
\end{tabular}

\section{Sonuç ve Öneriler}

Karabük ilindeki yapılan bu çalışmada demir çelik ve çimento fabrikalarının yakın çevresindeki alanlarda, toprak mikro eklembacaklılarının miktar ve çeşitliliği araştırılmıştır. Fabrikaya bakan yamaçla, zıt yönündeki, üniversite tarafındaki yamaç karşılaştırıldığında hem toprak özelliklerinde hem de eklembacaklıların miktar ve çeşitliliğinde anlamlı farklılıkların olduğu tespit edilmiştir. İki yamaç arasında, toprağın fiziksel özelliklerinden kil oranı ve nem içeriği fabrikaya bakan yamaçta önemli ölçüde az iken, kum oranı artmaktadır. Diğer yandan fabrikaya bakan yamaçta eklembacaklıların miktarı $\left(15463\right.$ birey· $\left.\mathrm{m}^{-2}\right)$ ve biyolojik çeşitliliği $\left(\mathrm{H}^{\prime}=1,91\right.$ ve $\mathrm{S}^{\prime}=$ 11), üniversiteye bakan yamaçtan $\left(47020\right.$ birey $\cdot \mathrm{m}^{-2}, \mathrm{H}^{\prime}=2,52$ ve $\left.\mathrm{S}^{\prime}=20,5\right)$ daha düşük bulunmuştur. Ayrıca, mikro eklembacaklıların toprak ekosisteminde oluşturmuş oldukları toplumlardaki besin ağının trofik seviyelerindeki birey oranları da farklılık göstermektedir. Üniversiteye bakan yamaçta çürükçüllerin oranı $(\% 62,5)$ doğal orman toprağındaki orana (\%70) daha yakın olmasına rağmen, fabrikaya bakan yamaçta çürükçüllerin oranı $(\% 50,6)$ önemli miktarda azalmaktadır. Yırtıcıların oranında da tersi bir durum belirlenmiştir. Doğal ormanda \%25 olan yırtıcıların oranı, kontrol alanında \%27,5, fabrika yönünde ise \%36,9’ a ulaşmıştır. Besin ağında av durumunda olan çürükçül ve otçul bireylerin oranı azalmasına rağmen, avcı olan yırtıcıların oran olarak artması, toplumda av kıtlığı oluştuğuna işaret etmektedir. Tüm bu bulgular birlikte ele alındığında, fabrika ve bacalarından yayılan kirleticilerin doğrudan temas ettiği yamacın toprak özelliklerini değiştirdiği düşünülmektedir. Yine aynı kirletici etki neticesinde, çürükçül beslenen eklembacaklıların zarar görerek azaldığı, buna bağlı olarak da besin ağındaki diğer trofik seviyelerdeki faunanın miktarının da azaldığı kanaati oluşmaktadır. Toprak eklembacaklılarında ortaya çıkan bu zararlı etkinin Söz konusu durum, fabrikaların çevreye yaptığı etkiler nedeniyle doğrudan etkilediği çevresinde, ekosisteme zarar verdiğini göstermektedir. Etkinin temelinde, fabrikalardan halen çevreye toksik maddelerin yayılmaya devam ediyor olması veya toprakta birikmiş olan kirleticilerin etkisinin halen ediyor olması da mümkün olabilir.

Toprak ekosistemini ve burada barınan eklembacaklı toplumlarına zarar veren, bu tür kirleticilerin etkisini tam olarak ortaya koymak için, toprakta kirletici madde analizlerinin yapılmasının yanı sıra atmosferik çökelme araştırmalarının da yapılması yerinde olacaktır. Bu alanlarda barınan diğer fauna elemanlarının bünyesinde kirletici (ağır metal, toksik madde vb) birikimleri araştırılmalıdır. Kirleticinin fauna üzerindeki olumsuz etki mekanizması (ölümcül toksik etki, kısırlaştırıcı vb) belirlenmelidir. Toprak eklembacaklılarında ortaya çıkan bu zararlı etkinin doğrudan veya besin zinciri yoluyla insanlara kadar ulaşmasını engelleyecek tedbirler geliştirilmelidir.

\section{Kaynaklar}

1. An, Y. J., Kim, S. W., Lee, W. M. (2013). The Collembola Lobelya sokamensis juvenile as a new soil quality indicator of heavy metal pollution. Ecological indicators, 27, 56-60.

2. Anonim (2012). Karabük Zonguldak Bartın İlleri Çevresel Durum Değerlendirmesi, S: 264, Karabük.

3. Anonim (2017). Karabük İli 2016 Y1lı Çevresel Durum Raporu, S:62, Karabük.

4. Anonim (2018). https://www.nufusu.com/ilce/merkez_karabuk-nufusu

5. Anonim (2019). https://karabuk.ktb.gov.tr/TR-63702/cografya.html

6. Butnariu, M. (2015). Markers, Indicators of Soil Pollution. In Environmental Indicators (pp. 343-364). Springer, Dordrecht.

7. Coleman, D. C., Crossley, D. A., Hendrix, P. F. (2004). Fundamentals of Soil Ecology, Academic press, USA.

8. Çepel, N. (1988). Orman Ekolojisi, İÜ Or. Fak. Yayın No, 389.

9. Dombos, M. (2002). A Tullgren-type extractor for sampling springtails populations from small volume soil cores in high sample size, Tiscia, 33, 3-7. 
10. Duyar, A. (2014). Toprak eklembacaklılarının (Arthropoda) Bolu-Aladağ göknar (Abies bornmulleriana Mattf.) ekosistemindeki mevsimsel değişimi. Doktora Tezi, İstanbul Üniversitesi, İstanbul, Türkiye.

11. Duyar, A. (2017). Fabrika baca kirliliğinin omurgasız toprak faunasına etkisi. III. Uluslararası Multidisipliner Çalışmaları Sempozyumu (ISMS), 12.10-11 Kasım 2017, Ankara.

12. Duyar, A. (2018a). Endüstri Kaynaklı Atmosferik Kirleticilerin Kuyrukla Siçrayanların (Collembola: Arthropoda) Miktar ve Çeşitliliğine Etkisi. International Congress on Engineering and Architecture (ENAR-2018), 14-16 Kasım 2018, 1261-1269, Antalya, Türkiye.

13. Duyar, A. (2018b). Diversity Of Soil Microarthropods In Habitats Containing Different Tree Species In The Spring Season. Fresenius Environmental Bulletin, 27 (12B), 9634-9641.

14. Duyar, A., Makineci, E. (2016). Seasonal and altitudinal variations of soil arthropods in Abies nordmanniana subsp. bornmulleriana forests. Bosque, 37(2), 335-345.

15. Faber, J. H., Wensem, J. (2012). Elaborations on the use of the ecosystem services concept for application in ecological risk assessment for soils, Science of The Total Environment, 415, 3-8.

16. Fiera, C. (2009). Biodiversity of Collembola in urban soils and their use as bioindicators for pollution. Pesquisa Agropecuária Brasileira, 44(8), 868-873.

17. Fischer, R., Mues, V., Ulrich, E., Becher, G., Lorenz, M. (2007). Monitoring of atmospheric deposition in European forests and an overview on its implication on forest condition. Applied Geochemistry, 22(6), 1129-1139.

18. Gülçur, F. (1974). Toprağın Fiziksel ve Kimyasal Analiz Yöntemleri. İÜ Yayınları, OF Yayın, (201), 225.

19. Hacısalihoğlu, İ. Y. (1994). Karabük’te Hava Kirliliği, Türk Coğrafya Dergisi, 29, 475-494.

20. Joo, S. J., Yim, M. H., Nakane, K. (2006). Contribution of microarthropods to the decomposition of needle litter in a Japanese cedar (Cryptomeria japonica) plantation, Forest Ecology and Management, 234, 192-198.

21. Kantarcı, D. (1980). Ilıman iklim koşullarında toprak kesitinde kilin taşınması ve birikmesi olayı üzerine araştırmalar. İstanbul Üniversitesi Orman Fakültesi Dergisi, 30(2), 153-190.

22. Karaöz, M. Ö. (1989). Toprakların su ekonomisine ilişkin bazı fiziksel özelliklerinin laboratuvarda belirlenmesi yöntemleri. İstanbul Üniversitesi Orman Fakültesi Dergisi, 39(2), 133-144.

23. Maaß, S., Daphi, D., Lehmann, A., Rillig, M. C. (2017). Transport of microplastics by two collembolan species. Environmental Pollution, 225, 456-459.

24. Meehan, T. D., Drumm, P. K., Schottland, F. R., Oral, K., Lanier, K. E., Pennington, E. A., Pennington, L. A., Stafurik, I. T., Valore, D. V., Wylie, A. D. (2006). Energetic equivalence in a soil arthropod community from an aspen-conifer forest. Pedobiologia, 50, 307-312.

25. Nakamura, A., Proctor, H., Catterall, C. P. (2003). Using soil and litter arthropods to assess the state of rainforest restoration. Ecological Management and Restoration, 4(s1) 20-28.

26. OGM (2019). https://www.ogm.gov.tr/Sayfalar/OrmanHaritasi.aspx

27. Özdalyan, B., Çelik, M. B., Kadı, İ. (2001). Karabük’te hava kirliliği ve çözüm önerileri. Teknoloji, 4(34), 51-56.

28. Özkan, K. (2012). Taksonomik çeşitlilik indislerinin geleneksel çeşitlilik indisleri ile karşılaştırılması. Turkish Journal of Forestry, 13(2), 107-112.

29. Posthuma, L. (1990). Genetic differentiation between populations of Orchesella cincta (Collembola) from heavy metal contaminated sites. Journal of Applied Ecology, 27(2), 609-622.

30. Salmon, S., Mantel, J., Frizzera, L., Zanella, A. (2006). Changes in humus forms and soil animal communities in two developmental phases of Norway spruce on an acidic substrate, Forest Ecology and Management, 237, 47-56.

31. Santorufo, L., Van Gestel, C. A., Maisto, G. (2012). Ecotoxicological assessment of metal-polluted urban soils using bioassays with three soil invertebrates. Chemosphere, 88(4), 418-425.

32. Santos, S. A. P., Cabanas, J. E., Pereira, J. A. (2007). Abundance and diversity of soil arthropods in olive grove ecosystem (Portugal): Effect of pitfall trap type, European Journal of Soil Biology, 43, 77-83.

33. Tovar-Sánchez, E., Hernández-Plata, I., Martínez, M. S., Valencia-Cuevas, L., Galante, P. M. (2018). Heavy Metal Pollution as a Biodiversity Threat. In Heavy Metals. IntechOpen.

34. Weidema, B. P. (2007). Framework for and review of biodiversity indicators for forest management in the context of product life cycle assessment. Draft report prepared for TetraPak. Hørsholm: 2.-0 LCA consultants.

35. Wiwatwitaya, D., Takeda, H. (2005). Seasonal changes in soil arthropod abundance in the dry evergreen forest of north-east Thailand, with special reference to collembolan communities. Ecological Res., 20, 5970 . 